\title{
INDIVIDUAL PERFORMANCE ASSESSMENT WITHIN CONTEMPORARY ORGANIZATIONS. A REVIEW OF TRANSFORMATIONAL SYSTEMS FOR EMPLOYEE EVALUATION
}

\author{
Siham Jibai \\ Bucharest University of Economic Studies, Romania \\ siham.jibai@hotmail.com \\ Kassem Hammoud \\ Bucharest University of Economic Studies, Romania \\ kassemhammoud@live.com
}

\begin{abstract}
Individual performance evaluations are usually performed annually, and they are related, directly or indirectly, to the economic performance of companies. The positive economic performance at the company level materializes mainly for the top management representatives in significant performance bonuses. The aim of the current paper is to investigate individual performance assessment within contemporary organizations. The research methodology proposes a thorough literature review of the relevant research conducted in the last decades. The paper analyses the conflict between measurement and development functions of an individual performance assessment system, it investigates the transformational perspectives on individual performance assessment in modern organizations and it identifies opportunities for improving employee evaluation system by providing a productive framework for individual performance assessment based on literature review.

Keywords: Individual performance evaluations, transformational perspectives, improving employee evaluation, employee performance assessment.
\end{abstract}

\section{INTRODUCTION}

The imbalances of the world economy have been generated and maintained by private companies which, through immediate profit-oriented thinking, have contributed to the shift of production centers, but also productivity, to developing countries such as China, India, Brazil, etc. By creating financial instruments that exploited system flaws, large financial companies created artificial value that was not based in many cases on economic added value. 


\section{INDIVIDUAL PERFORMANCE ASSESSMENT WITHIN CONTEMPORARY ORGANIZATIONS. A REVIEW OF TRANSFORMATIONAL SYSTEMS FOR EMPLOYEE EVALUATION}

The evaluation of companies based on simplistic indicators allowed the definition of growth indicators for companies, but even for some industries and markets that did not have a solid correspondent in the real economy, but rather one based on speculative influences and a spiral lending, facilitated by relaxed bank rules lending and sometimes financial instruments with poor coverage in the real market.

One of the main causes of the previous economic crisis was the narrow way in which companies define the concept of value created, optimizing short-term financial performance and ignoring the broad influences that determine long-term success. Policymakers in the world's major economies appear to be concerned with finding ways to link the economic performance of value-creating process companies with real impact on society as a whole. Large corporations also seem to be concerned with processes to demonstrate their concern for social responsibility. Although in many cases corporate social responsibility is in many cases seen by large corporations as image exercises whose costs are needed as an effective means of responding to societal pressures, there are companies that are truly concerned about the social impact of their activities. Because they aim to increase economic performance at the company level, performance systems are the ones that most accurately reflect the practical ways of action of organizations and their real interests. Within companies, the real responsibility manifests itself at the individual level - therefore, the analysis of individual performance systems within companies gives the most viable indications of the real values of the company, through the criteria used, the measurement method that is consistent with the philosophy applied in practice by that organization.

Individual performance cycles are in most cases annual, usually related, directly or indirectly, to the economic performance of companies, which are mainly evaluated annually. The positive economic performance at the company level materializes mainly for the top management representatives in significant performance bonuses. Other economic actors, such as investment banks, financial analysts, capital market specialists, have an interest in demonstrating economic development and growth - also given that most industrialized countries have 4-year political cycles, politicians support the good news from -a world economy not only based, but also dependent on economic growth.

The short-term orientation of many companies is accelerated by individual performance systems. Most large companies use individual performance cycles on an annual basis. Within these companies, top management negotiates annual performance targets that it assumes in the form of management contracts. Achieving performance goals materializes primarily for management representatives through significant bonuses - thus, the short-term orientation of many companies is accelerated by individual performance systems that support the achievement of top management goals. Because shareholders are directly interested in economic performance, the cases in which they have intervened to require companies in which they have invested to assume increased social responsibility is very small. They often operate in 
non-profit organizations, and the companies in which they invest follow the same rules of the economic game in which economic performance is validated by annual budget exercises.

\section{LITERATURE REVIEW}

The negative reactions of employees as a result of individual performance assessment processes have been reported both by numerous academic studies (Culbertson et al, 2013) and by the decisions that some companies make. Not having time to do everything right, most managers neglect informal conversations that could provide feedback on performance and support (Pulakos and O'Leary, 2011). Research confirms managers' reluctance and Kuvaas (2011) argues that despite individual performance assessment rhetoric and the impact on workplace engagement and performance, these relationships are assumed rather than tested. Among the problems recognized by managers are unclear or changing organizational priorities and goals, in many departments these being a consequence of the new pace and speed of adaptation; another cause is organizational uncertainty - derived from external conditions, such as shorter market cycles.

As most evaluation systems have a one-year cycle, and as the mid-year review is a formality, it is increasingly difficult to base discussions on individual performance on facts and data related to evaluators' efforts, all the more so as new technologies increase the complexity of operations and there are more hidden interdependencies operating in organizational life (Shao et al., 2016). Projects, regardless of scale, with different stakeholders and participants, are another major influence, given that formally or informally, many people are co-opted and work in inter-departmental projects (Brown, 2019).

\section{RESEARCH METHODOLOGY}

The current paper focuses on investigating individual performance assessment within contemporary organizations. The research methodology is based on documentary analysis and included a detailed analysis of published articles and books regarding the measurement and development functions of an individual performance assessment system, the need to reform performance systems, transformational perspectives on individual performance assessment. The proposed research objectives are the following:

Objective 1: Analyzing the conflict between measurement and development functions of an individual performance assessment system;

Objective 2: Investigating the transformational perspectives on individual performance assessment in modern organizations; 
Objective 3: Identifying opportunities for improving employee evaluation system: providing a productive framework for individual performance assessment based on literature review.

\section{ANALYSING THE CONFLICT BETWEEN MEASUREMENT AND DEVELOPMENT FUNCTIONS OF AN INDIVIDUAL PERFORMANCE ASSESSMENT SYSTEM}

There is a conflict between the measurement and development functions of an individual performance assessment system and their consequences at the level of employees, highlighted by most studies on the organizations that have implemented this system (Phillips \& Phillips, 2016). Thus, each employee may have conflicting objectives when evaluating individual performance if this evaluation is related to the granting of extrinsic rewards (Landy et al., 2017). The conflict stems from the opposing interests of two critical issues: measurement and development and future orientation. Employees tend to present their own activity and performance in a favorable light, because the results of this assessment will have a substantial influence on the extrinsic rewards (salaries, awards, promotions, transfers) that will be given. Therefore, many employees avoid sharing the problems they face, which will be attributed either to other people or to organizational system deficiencies.

On the other hand, employees want fair and constructive feedback on their own performance. They recognize the benefit of an open and constructive discussion regarding the problems encountered in their activity, ways to improve it and establish a personal development plan in order to meet the performance standards established at the level of the position they hold within the organization.

Many organizations have realized the danger of a direct link between rewards and performance at the same time as using the appreciation system for other purposes such as: identifying training needs, professional development, identifying potential employees, etc. The solution found to this conflict, taking into account the rationality of the direct link between performance and salary decisions, was a separation in time and in procedures between the system of appreciation of individual performances and the system of remuneration.

Thus, the assessment of individual performance in relation to the performance standards established for the position held for professional development is carried out formally or informally throughout the year, during meetings between the assesse and the evaluator, and action plans are established based on these assessments for each individual employee to meet the established performance requirements. This creates a climate of trust and openness in the relationship between the evaluator and the evaluator, conditioned by the way in which the information obtained from the assessment of individual performance is used by the evaluator and, implicitly, by the organization. Salary, promotion or transfer decisions are made based on another standardized procedure within the organization, based on 
information obtained during the last meeting to assess professional performance during a year of evaluation.

As important as being aware of this potential conflict between the objectives for which an individual performance appraisal system is designed and used and acting accordingly is the clarification of these objectives and the benefits of implementing the system for all parties involved in the process.

Without this necessary clarification before designing and implementing the assessment system, the experience of a relevant number of organizations demonstrated the degeneration of the process into a ritual, perceived by the parties as meaningless, a simple exercise of filling in a form unrelated to people's work or the real problems they face, existing in the organization.

Although positive feedback takes precedence, the conclusions drawn are, in many cases, plans to improve a list of shortcomings, defects, opportunities for improvement and other politically accepted names and terms that denote weakness, and which the valued person feels not only as reproaches, but also as a sign of distrust.

These plans are created to provide more control and predict future successes as part of a problemsolving process. However, the presence of areas for improvement in a plan for the future may decrease a person's motivation to contribute to organizational goals (Roberts et al, 2005). Without the help of a close relationship based on mutual trust, this is perceived as an expression, often written, of the statement "you are not good enough yet".

\subsection{The need to reform performance systems}

Instrumental systems for assessing individual performance, although producing remarkable results in the first years of use within companies, have a limited effect on individual productivity increases, through the limited incremental effects they produce, mainly due to the transactional management they it is also based on the conflicts that have arisen within the system. New approaches are needed, with changes in: perspectives and paradigms, which produce the desired results, a framework that takes into account the needs of current employees, as well as adaptive practices.

\subsection{The need to accept new perspectives}

Despite the success of emotional intelligence trends, managers with a traditionalist approach perceive themselves as pragmatic, realistic, and problem-solving and improvement oriented. Based on this belief, many systems for assessing individual performance focus on finding solutions to problems that have not yet been resolved and on how the appraiser and sometimes the appraiser, as part of the problem, needs to improve. A new reality is more recently accepted by managers: that in which facts, knowledge and even data are subject to interpretation. 
Weick (2009) proposed an interpretive approach to understanding organizations: as meaningful systems, in which members interact through dialogue and where these social interactions build and shape organizational reality. These social constructs are used not only to understand and represent reality but also as cultural guides for behaviors.

The links between individual performance assessment results and reward, promotion and other important decisions in organizational life, make individual performance assessment discussions stressful, tense and even turn them into traumatic events. Managers' observations can be explained using the transactional theory of stress (Biggs et al., 2017; Loewenstein et al., 2019), according to which the stressors present in the performance evaluation do not directly trigger a stress reaction, but rather the perceived perception and concerns about the challenge are what determine this reaction. As a result, more and more managers are now taking into account employees' personal feelings about work and job satisfaction levels, but less appreciating the positive impacts of performance appraisal systems.

\section{TRANSFORMATIONAL PERSPECTIVES ON INDIVIDUAL PERFORMANCE} ASSESSMENT

The management processes of organizational and individual performance play a central role in the activity of each company. The transformational managerial perspectives proposed by the big companies to their own management also find a correspondent in the systems for assessing individual performance (El Toufaili, 2018; Alidadi \& Zaboli, 2019). In addition to the instrumental approach used in the practice of most organizations that use individual performance appraisal systems, Fleischer and Christie (2009) show other perspectives, for example: conceptual, illuminating, persuasive, procedural, used to generate individual performance assessment-related information (Figure 1).

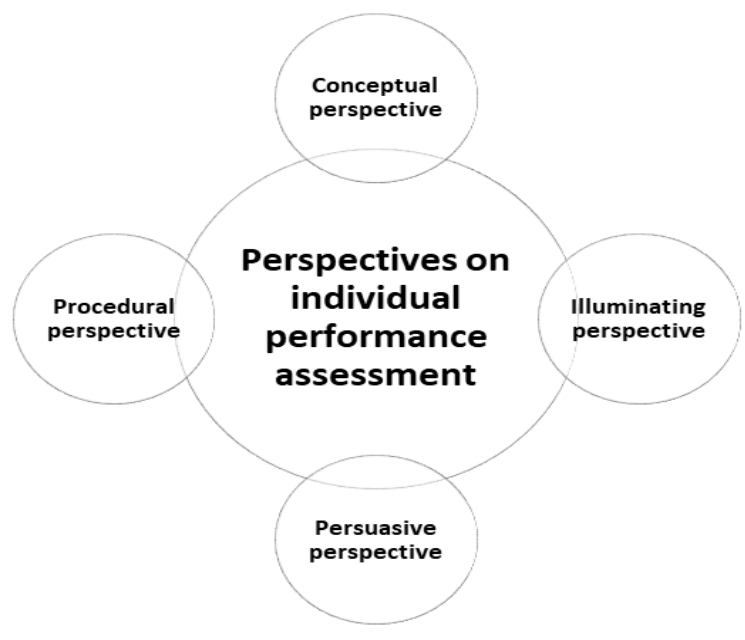

Figure 1. Perspectives on individual performance assessment Source: Created by authors, based on literature review 


\section{a. Conceptual perspective}

The actors involved understand the evaluated aspects in a new way, which allows them both to define some conclusions regarding the productive processes, and to plan some modifications of the value generating processes both in the work of the appreciated person and in other stakeholders, e.g. the direct manager or managers of higher levels.

\section{b. Illuminating perspective}

The results of performance evaluation allow the development of knowledge in other organizational areas, which can be used in a broad context of organizational performance. Thus, useful information for managers was highlighted about:

- information flows,

- unclear roles and responsibilities,

- systemic problems,

- differently understood organizational norms and conflicts related to misunderstandings.

\section{c. Persuasive perspective (symbolic)}

Through the processes of appreciation of individual performances, strong messages are transmitted in the organization - for example, it is shown that responsibility is appreciated in the organization, as a general message, by clarifying practical and pragmatic aspects, at the level of achieved indicators and associated behaviors.

A relevant, corrective example related to occupational safety is the case of a company in the automotive industry, which has as an eliminatory condition in the reward system the existence of serious accidents for subordinate staff. Thus, by connecting the reward system with the individual performance appraisal system, for managers of different hierarchical levels, but also other complementary measures of reactive control and proactive awareness measures, a very strong message of zero tolerance towards deviations to the norms of labor protection was transmitted in the organization. Thus, in case of a work accident with serious consequences, all the hierarchical managers of the injured person lose their right to the annual performance bonus, a measure that can be followed by other administrative sanctions. The individual assessment form contains a special chapter that specifies both objective measures and measurements (indicators) and behaviors.

\section{d. Procedural perspective - interventions in social systems and process systems}

Learning processes derived from evaluative processes lead to cognitive, behavioral and organizational changes. Oppl and Stary (2019) show that the procedural perspective refers to and is indicated by 


\section{INDIVIDUAL PERFORMANCE ASSESSMENT WITHIN CONTEMPORARY ORGANIZATIONS. A REVIEW OF TRANSFORMATIONAL SYSTEMS FOR EMPLOYEE EVALUATION}

individual changes in thinking and behavior and changes in programs or organizational procedures or culture.

\section{The essential benefit of individual performance assessment perceived by managers}

The main advantage of using the individual performance assessment is the ability of managers to support employees to understand the objectives of the team but also the individual, namely to clarify:

The link between long-term organizational goals and interests and their contribution to the added value brought by the company,

The connection with the goals of the organization and the annual objectives, both in terms of results and expected behaviors,

Major interests of the department and other important partners (Their identification - Who are they?; What interest do they have?; What power and influence do they have?),

Relative priority of individual objectives (including by relative weighting),

Ways to define success (including means of measurement),

Necessary and expected resources and support.

2. Systemic aspects of individual performance assessment

A productive use of individual performance assessment should generate the following useful aspects:

1. Personal or organizational learning,

a. Clarification of some concepts, related to: appreciation of collaborators as a daily process, motivation, perceptions, communication (feedback, information, etc.) and organizational priorities.

b. Skills development, namely: administration (collection of information, procedures, etc.), leadership (motivation and cultivating commitment), cognitive, one-on-one communication, understanding and accepting different perspectives

c. Analysis and clarification of some managerial processes.

2. Changes in actions or behaviors,

a. Personal reflection on: mode of action, personal contributions - what is appreciated and what is not by others, personal productivity - "what is worth doing and what is not", differences between personal intentions and the effect felt by collaborators.

b. Decisions to act differently: repetition of useful behaviors, decreasing the frequency (or elimination) of unproductive behaviors, clearer and better understood action plans by collaborators, defining new indicators, delegating tasks and empowering collaborators. 
3. Changes in affection or attitudes

a. Increasing the level of commitment

b. Openness

c. Improving the team climate

d. Respect for others, by accepting the differences of: perceptions, things, perspectives.

e. Increasing collaboration

f. Clarification of expectations

g. Increasing self-esteem

Although these aspects are seen as useful by all stakeholders of individual performance assessment systems, their appearance as well-defined and followed results leaves much to be desired, even if both the company and the employee-direct manager pair have very good results.

\section{Contribution to organizational transformation}

a. Improving key processes: making a decision; panning and clarifying team and personal goals; reagents - analysis, measurements; proactive - commitment, innovation, etc.; network development and inter-departmental collaboration.

These interests described above lead to the idea of a significant managerial evolution - a strong reorientation towards the context of the activity and the individual context (in terms of commitment), and less about the narrow structuring and planning, especially due to the low predictability of the external context of companies, which leads to increased flexibility needs.

When implementation and practice are good, the activities of the individual performance assessment system generate feedback that can contribute to understanding the foundations of past successes to create organizational knowledge and direct future efforts. Individual performance assessment discussions were also appreciated as being seen as having a majority of a relaxing effect, as they have the potential to reduce problems such as:

a. Conflicts related to the ambiguity of roles - related to frustration and anxiety;

b. Ambiguity of roles - related to frustration, anxiety, job satisfaction;

c. Workload and responsibilities;

d. Dissatisfaction with the job, which generates anxiety, frustration and the intention to leave the organization. 


\section{CONTRIBUTIONS: IDENTIFYING OPPORTUNITIES FOR IMPROVEMENT - PRODUCTIVE FRAMEWORK FOR INDIVIDUAL PERFORMANCE ASSESSMENT}

The problems highlighted by the qualitative methods can be found in the table below, which uses a framework suggested by Schneier et al. (1995):

Table 1. Productive framework for individual performance assessment

\begin{tabular}{|c|c|}
\hline hat should be improved in organizations: & anies need: \\
\hline $\begin{array}{l}\text { - A simple evaluation form completed by } \\
\text { the employee; } \\
\text { - Score made by the hierarchical superior; } \\
\text { - Orientation of performance evaluation } \\
\text { towards the past; } \\
\text { - Measuring generic issues related to } \\
\text { - } \text { people or the job; } \\
\text { Consequences of achieving performance } \\
\text { - } \text { Rentered around the basic salary; } \\
\text { department for solving problems in the } \\
\text { - evaluation system; } \\
\text { Ambiguity and inconsistency in defining } \\
\text { performance expectations at different } \\
\text { levels, for different managers; } \\
\text { Performance goals set too low or not at } \\
\text { all for the organization's competitiveness. }\end{array}$ & $\begin{array}{l}\text { - A management tool or process; } \\
\text { - Multidimensional appreciation, made by } \\
\text { subordinates, direct manager, colleagues } \\
\text { and clients; } \\
\text { - Orientation towards setting expectations for } \\
\text { the future, continuous development and } \\
\text { improvement; } \\
\text { - Measuring "Key Success Factors" to } \\
\text { ensure the implementation of the strategy; } \\
\text { - Positive and negative, financial and non- } \\
\text { financial consequences of the performance } \\
\text { actually used; } \\
\text { - Making managers responsible for } \\
\text { designing, leading and improving the } \\
\text { process using human resources support; } \\
\text { - Transparency in defining success for } \\
\text { individuals, teams, departments within the } \\
\text { company; } \\
\text { - Incentive goals, constantly growing, } \\
\text { reflecting the constant increase in customer } \\
\text { expectations and competitors' skills. }\end{array}$ \\
\hline
\end{tabular}

Source: Generated by authors, based on literature review 


\section{Jibai S. and Hammoud K. \\ INDIVIDUAL PERFORMANCE ASSESSMENT WITHIN CONTEMPORARY ORGANIZATIONS. A REVIEW OF TRANSFORMATIONAL SYSTEMS FOR EMPLOYEE EVALUATION}

\section{CONCLUSIONS}

The conditions for survival in the current economic environment are increasingly harsh, as it requires the multidimensional alignment of companies to high performance standards. Traditionally, these highperformance standards have been maintained through the organizational implementation of performance measurement systems and reactive response systems.

At the state level, due to global economic systems in which capital flows more and more easily, large economies cannot afford to impose economic rules that could in the short term be penalizing for those who would propose, through tax systems (the levers more effective at the disposal of states) an orientation towards long-term effects. Paradoxically, the engine that supports change in large companies seems to be an internal one: economic performance in today's economy, increasingly based on uncertainty and lack of predictability, is increasingly affected by staff engagement. And this is difficult to achieve in the current framework of reactive individual performance appraisal systems, based on past performance.

\section{REFERENCES}

Alidadi, A., \& Zaboli, R. (2019). Evaluation of Effective Components on Transformational Leadership in Managers of an Iranian Hospital from Perspective of Employee; an Analytical Study. Health Research Journal, 4(1), 38-46.

Biggs, A., Brough, P., \& Drummond, S. (2017). Lazarus and Folkman's psychological stress and coping theory. The handbook of stress and health, 349-364. doi:10.1002/9781118993811.ch21

Brown, M. (2019). Understanding Performance Appraisal: Supervisory and Employee Perspectives. The SAGE Handbook of Human Resource Management, 195.

Culbertson, S. S., Henning, J. B., \& Payne, S. C. (2013). Performance appraisal satisfaction. Journal of Personnel Psychology, 12(4), 189-195.

El Toufaili, B. (2018). The influence of subjective factors on the development of the transformational style of leadership. Revista de Management Comparat International, 19(2), 124-135.

Fleischer, D. N., \& Christie, C. A. (2009). Evaluation use: Results from a survey of US American Evaluation Association members. American Journal of Evaluation, 30(2), 158-175. DOI: $10.1177 / 1098214008331009$.

Kuvaas, B. (2011). The interactive role of performance appraisal reactions and regular feedback. Journal of Managerial Psychology, 26, 123-137.

Landy, F., Zedeck, S., \& Cleveland, J. (2017). Performance measurement and theory. Routledge.

Loewenstein, K., Barroso, J., \& Phillips, S. (2019). The Experiences of Parents in the Neonatal Intensive Care Unit: An Integrative Review of Qualitative Studies Within the Transactional Model of Stress and Coping. The Journal of perinatal \& neonatal nursing, 33(4), 340-349. 
Oppl, S., \& Stary, C. (2019). Alignment of Multiple Perspectives: Establishing Common Ground for Triggering Organizational Change. In Designing Digital Work (pp. 133-178). Palgrave Macmillan, Cham.

Phillips, J. J., \& Phillips, P. P. (2016). Handbook of training evaluation and measurement methods. Routledge.

Pulakos, E. D., \& O'Leary, R.S. (2011). Why is performance management broken? Industrial and Organizational Psychology: Perspectives on Science and Practice, 4(2), 146-164.

Roberts, L. M., Dutton, J. E., Spreitzer, C. M., Heaphy, E. D., \& Quinn, R. E. (2005). Composing the reflected best-self portrait: Building pathways for becoming extraordinary in work organizations. Academy of Management Review, 30(4), 712-736.

Schneier, C. E., Shaw, D. G., Beatty, R. W., \& Baird, L. S. (Eds.). (1995). Performance measurement, management, and appraisal sourcebook. Human Resource Development.

Shao, Z., Feng, Y., \& Hu, Q. (2016). Effectiveness of top management support in enterprise systems success: a contingency perspective of fit between leadership style and system life-cycle. European Journal of Information Systems, 25(2), 131-153.

Weick, K. (2009). Making sense of the organization: The impermanent organization (Vol. 2). Chichester, England: Wiley. 